\title{
Depurination of Nucleosides and Calf Thymus DNA Induced by 2-Bromopropane at the Physiological Condition
}

\author{
Jyoti Sherchan, Hoyoung Choi, and Eung-Seok Lee*

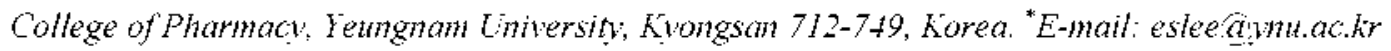 \\ Received Julv 28, 2009, Accepted August 25, 2009
}

\begin{abstract}
Depurination, the release of purine bases from nucleic acids by hydrolysis of the $N$-glycosidic bond, gives rise to alterations of the cell genome. Though cells have evolved mechanisms to repair these lesions, unrepaired apurinic sites have been shown to have two biological consequences: lethality and base substitution errors. 2-Bromopropane $(2-\mathrm{BP})$ is used as an intermediate in the synthesis of pharmaceuticals, dyes, and other organics. In addition, 2-BP has been used as a replacement for chloroflurocarbons and 1,1,1-trichloroethane as a cleaning solvent in electronics industry. However, 2-BP was found to cause reproductive and hematopoietic disorders in local workers exposed to it. Oring to the toxicity of 2-BP, there has been a tendency to use l-BP as an altenative cleaning solvent to 2-BP. However, I-BP has also been reported to be neurotoxic in rats. Though $x$-guanine adduct of 2 -BP has been reported previously, massive depurination of the nucleosides and calf thymus DNA was observed in this study. We incubated the nucleosides ( $\mathrm{ddG}, \mathrm{dG}$, glanosine, $\mathrm{ddA}, \mathrm{dA}$ and adenosine) with excess amount $2-\mathrm{BP}$ at the phy siological condition $\left(\mathrm{pH} 7.4,37^{\circ} \mathrm{C}\right.$ ), which were analyzed by HPLC and LC-MS/MS. In addition, the time and dose response relationship of depurination in nucleosides induced by 2-bromopropane at the physiological condition was investigated. Similarly, incubation of calf-thymus DNA with the excess anount 2-BP at the physiological condition was also performed. In addition, the time and dose response relationship of depurination in calf-thymus DNA induced by 2-BP at the physiological condition was investigated. Those results suggest that the toxic effect of 2 -BP could be both from the depurination of nucleosides and DNA adduct fomation.
\end{abstract}

Key Words: Depurination. Nucleosides. Calf-thỵmus DNA. 2-Bromopropane. Dose and time response relationship

\section{Introduction}

The depurination of micleic acids. the release of purine bases from nucleic acids by hydrolysis of the $\mathrm{N}$-glycosidic bond (Fig. 1). gives rise to alterations of the cell genome. ${ }^{\text {l. }}$ The apurinic sites resulting from depurination are quite stable, ${ }^{3}$ and cells have evolyed mechanisms to repair these lesions. ${ }^{+}$However, unrepaired apurinic sites have been shown to have two biological consequences: lethality ${ }^{5.6}$ and base substitution errors. ${ }^{6}$ Depurination leaves the DNA phosphodiester backbone intact and leaves apurinic site. Apurinic sites are excellent candidates for becoming the causative lesions: they are mutagenic in wivo only after induction of $\mathrm{SOS}^{6.8}$ system and they induce $\mathrm{G}: \mathrm{C} \rightarrow \mathrm{T}: \mathrm{A}$ and $\mathrm{A}: \mathrm{T} \rightarrow \mathrm{T}: \mathrm{A}$ transversions characteristically as a result of preferential insertion of adenine residues opposite apurinic sites during DNA replication ${ }^{9,11}$ resulting in base substitution errors. More recently. it has been reported that in early preneoplastic mouse skin, apurinic sites formed by the $\mathrm{PAH}$ carcinogen dibenzo[a.l] pyrene (DB[a.1]) undergo error-prone repair to form tumor-intitiating $\mathrm{H}$-ras mutations. ${ }^{11}$ by inducing pre-replication repair that is error-prone and forms mismatched heteroduplexes leading to transforming mutations in $\mathrm{H}-$ ras gene at codon 61 (CAA to CTA).

It has been reported by the Hazardous Substances Data Bank (HSDB) ${ }^{13}$ that 2-bromopropane (2-BP) is used as an intermediate in the synthesis of phammaceuticals. dyes. and other organics. The extent of their uses and associated human exposures is unknown. 2-BP (CAS No. 75-26-3) has been used as a cleaning solvent in the electronics industry in order to replace chloroflu-
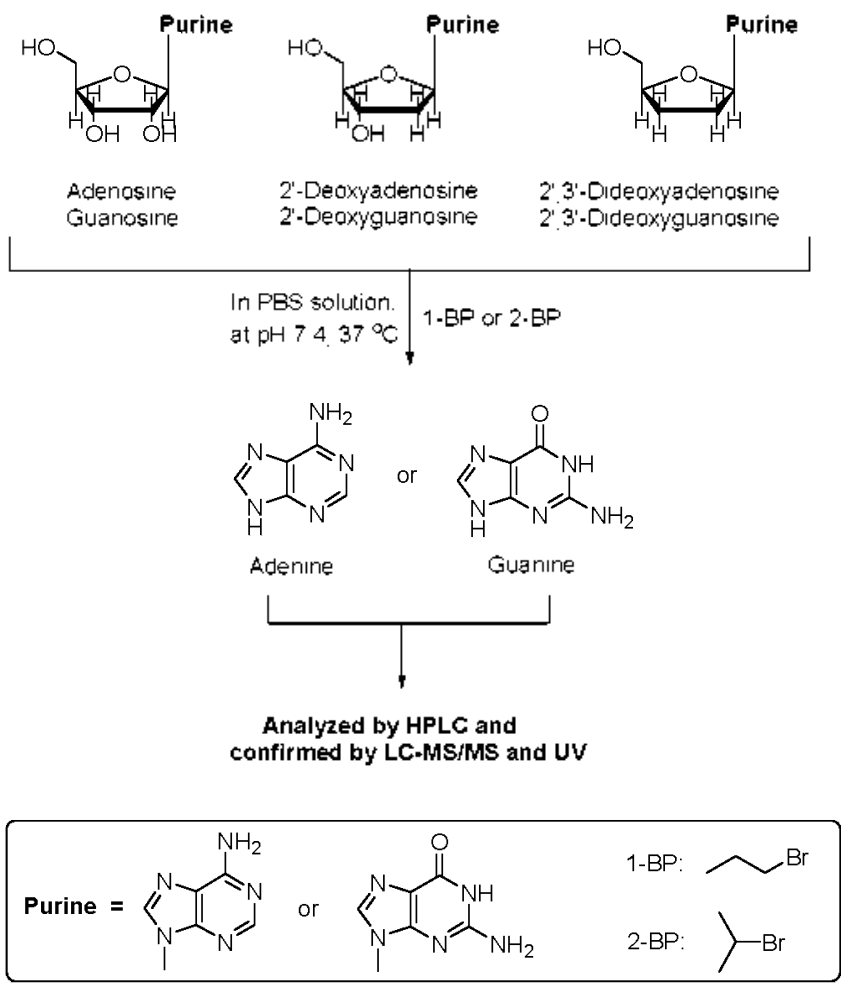

Figure 1. Scheme of depurination, the release of purine bases from nucleic acids by hydrolysis of the $\mathrm{N}$-glycosidic bond. Adenine and guanine based-nucleosides were incubated with l-BP or 2-BP at the physiological condition $\left(\mathrm{pH} 7.4,37^{\circ} \mathrm{C}\right)$ and analyzed by HPLC and contimed by LC-MS/MS and UV. 
orocarbons (CFCs) and 1,1.1-trichloroethane ${ }^{14,15.16,17}$ as their use and production became prohibited in developed countries since January $1^{\text {st }} 1996$. following the international agreement for the protection of the ozone layer. ${ }^{18}$ But in 1995 . an outbreak of reproductive and hematopoietic disorders occurred in male and female workers exposed to a solvent containing $2-\mathrm{BP}$ as a major ingredient in an electronics factory in South Korea. ${ }^{14.16 .19}$ which caused the Korean Ministry of Labor to establish the threshold limit value (TLV) for 2 -BP in the workplace as $1 \mathrm{ppm}^{20}$ Owing to the toxicity of 2-BP. there has been a growing tendency to use 1-bromopropane (1-BP) as an alternative cleaning solvent to 2-BP. However. 1-BP cause a depressing action on the central nervous system $(\mathrm{CNS})^{3]}$ and is reported to cause irritation to the skin and ey'es of mice. ${ }^{\text {n }}$ But the details of I-BP toxicity have not been stidied well until recently. Presently. 1-BP is still used in the work place despite insufficient information regarding its toxicity ${ }^{\text {?3 }}$

We have reported that formation of $N^{7}$-guanine adducts $\left(\mathrm{N}^{7}\right.$. propyl guanine or $N$-isopropyl guanine. respectively) in DNA by 1-BP or 2-BP would be one of the mechanisms for its toxicity. ${ }^{24}$ However, we observed massive depurination of nucleosides such as $2^{\prime} .3^{\circ}$-dideoxyadenosine (ddA). $2^{\circ}$-deoxyadenosine $(\mathrm{dA}),{ }^{35} 2: 3^{\circ}$-dideoxyguanosine (ddG). $2^{\prime}$-deoxyguanosine $(\mathrm{dG}){ }^{25}$ and calf thymus DNA when the nucleosides and calf thymus DNA were incubated with an excess amount of 2-BP at the physiological condition.

\section{Methods and Materials}

Chemicals and reagents. 1-Bromopropane (1-BP. 99\%). 2bromopropane (2-BP. 99\%), 2'-deoxyadenosine (dA. 99 100 \%). 2'-deoxyguanosine hydrate ( $\mathrm{dG}, 99 \%$ ), adenosine (Ado. 99\%), guanosine hydrate (Guo, 98\%). calf-thymus DNA (deoxyribonucleic acid sodium salt from calf thy'mus). 5-flurouracil (5-FU. 99\%), 5-flurouridine(5-FUri, 99\%), phosphate buffered saline ( $\mathrm{pH} 7.4$ ) and ammonium acetate $(99.995+\%$ ) were purchased from Sigma Aldrich Co. (ST. Louis. MO) . 2'3\%'Dideoxyadenosine (ddA) and $2^{\prime} \cdot 3^{\circ}$-dideoxyguanosine (ddG) were obtained from Berry \& Associates Inc. 9-Methyl adenine was prepared in our lab. HPLC grade acetonitrile and methanol was purchased from World Science. Korea

Preliminary reactions. One mg of nucleoside (ddA. dA. adenine $d d G . d G$ and guanine) was dissolved in $1 \mathrm{~mL}$ phosphate buffered saline solution (PBS) in $5 \mathrm{~mL}$ vial. Ten $\mu \mathrm{L}$ (5 $\mathrm{mg}$ in 1 $\mathrm{mL}$ PBS) of 5-flurouridine (5-FUni) for adenine-based nucleosides and $20 \mu \mathrm{L}$ ( $10 \mathrm{mg}$ in $1 \mathrm{~mL}$ PBS) of 5-flurouracil (5-FU) for guanine-based nucleosides was added as an internal standard. respectively: It was then incubated with excess amount ( $5 \mathrm{I} 2$ equivalents) of $1-\mathrm{BP}$ or $2-\mathrm{BP}$ at the physiological condition for $48 \mathrm{~h}$. Then it was analyzed by HPLC and further confirmed by LC-MS/MS. All the reactions were repeated for three times.

Time response reaction One $\mathrm{mg}$ of nucleoside (ddA, dA, ddG and $\mathrm{dG}$ ) was dissolved in $1 \mathrm{~mL}$ phosphate buffered saline solution (PBS) in $5 \mathrm{~mL}$ vial separately. Ten $\mu \mathrm{L}$ ( $5 \mathrm{mg}$ in $1 \mathrm{~mL}$ PBS) of 5-flurouridine (5-FUri) for adenine-based nucleosides and $20 \mu \mathrm{L}$ (10 $\mathrm{mg}$ in $1 \mathrm{~mL}$ PBS) of 5 -flurouracil (5-FU) for guaninebased nucleosides was added as an internal standard, respectively. It was then incubated with excess amount ( 512 equivalent) of 2-BP at the plysiological condition. About $10 \mu \mathrm{L}$ of samples were withdrawn after time interval of $\mathrm{I}$ and $3 \mathrm{~h}$, respectively. for dideoxy and deoxy nucleosides and then analyzed by HPLC until $100 \%$ depurination occurred. All the reactions were repeated for three times.

Dose response reaction One mg of nucleoside (ddA, dA, ddG and $\mathrm{dG}$ ) was dissolved in $1 \mathrm{~mL}$ phosphate buffered saline solution (PBS) in $5 \mathrm{~mL}$ vial separately. Ten $\mu \mathrm{L}$ (5 $\mathrm{mg}$ in $1 \mathrm{~mL}$ PBS) of 5-flurouridine (5-FUri) for adenine-based nucleosides and $20 \mu \mathrm{L}$ ( $10 \mathrm{mg}$ in $1 \mathrm{~mL}$ PBS) of 5-flurouracil (5-FU) for guaninebased nucleosides was added as an intenal standard. respectively. It was then incubated with different amounts $(0,2,4,8,16$. $32,64,128.256$ and 512 equivalents) of 2-BP at the physiological condition for a time period at which $100 \%$ depurination occurred according to time response reaction, which was identified as $24 \mathrm{~h}$. Again the samples were analyzed by HPLC and repeated for three times.

Reactions with calf-thymus DNA (ct-DNA). Two mg of ctDNA was dissolved in $20 \mathrm{~mL}$ of PBS solution and $40 \mu \mathrm{L}$ of 9 methyl adenine ( $0.5 \mathrm{mg}$ in $1 \mathrm{~mL}$ PBS) was added as an intemal standard and stirred to mix properly. One $\mathrm{ml}$ of the above prepared solution of ct-DNA was taken in $5 \mathrm{~mL}$ vial and incubated with $128 \mu \mathrm{L}$ of $2-\mathrm{BP}$ at the physiological condition for $48 \mathrm{~h}$ as a preliminary reaction. At the end of the reaction $300 \mu \mathrm{L}$ of I M aqueous $\mathrm{HCl}$ was added and centrifuged for 10 min at 13,000 $\mathrm{rpm}$. Then the supernatant was analyzed by LC-MS/MS under the condition mentioned below.

Time response reaction was performed with $128 \mu \mathrm{L}$ of $2-\mathrm{BP}$ at a time interval of $8 \mathrm{~h}$ for $0.8,16,24,32,40$ and $48 \mathrm{~h}$. Again. at the end of the reaction $300 \mu \mathrm{L}$ of $1 \mathrm{M}$ aqueous $\mathrm{HCl}$ was added and centrifuged for $10 \mathrm{~min}$ at $13,000 \mathrm{rpm}$. Then the supernatant was analyzed by LC-MS/MS under the condition mentioned below.

Dose response reaction was performed with $2,4,8,16.32$. 64 and $128 \mu \mathrm{L}$ of 2 -BP separately for $48 \mathrm{~h}$. Again, at the end of the reaction $300 \mu \mathrm{L}$ of $\mathrm{I} \mathrm{M}$ aqueous $\mathrm{HCl}$ was added and centrifuged for $10 \mathrm{~min}$ at $13.000 \mathrm{rpm}$. Then the supernatant was analyzed by LC-MS/MS under the condition mentioned below.

Calculation fordepurination ratio in nucleosides. Depurination ratio (DR\%) was calculated on the basis of the decreased amount of the nucleosides in percentage by comparing the integration value of the nucleosides in HPLC using the formula below:

$$
\text { Depurination ratio }(\%)=\frac{\frac{\mathrm{A}_{\odot}}{\mathrm{IS}}-\frac{\mathrm{A}_{\mathrm{L}}}{\mathrm{IS} \mathrm{S}_{\mathrm{t}}}}{\frac{\mathrm{A}_{\circ}}{\mathrm{I} \mathrm{S}_{\odot}}} \times 100 \%
$$

where ' $\mathrm{A}_{0}$ ' is the initial amount of nucleoside; " $\mathrm{A}_{i}$ ' is the amount of nucleoside after time. $t$ : ' $I S_{c}$ ' is the initial amount of internal standard and ' $I S_{t}$ ' is the amount of nucleoside after time. $t$.

Calculation for depurination ratio in ct-DNA. Depurination ratio (DR) was calculated on the basis of the increased amount of adenine or guanine compared with the internal standard (IS) by comparing the integration value in EIC from LC-MS/MS using the formula below: 


$$
\begin{aligned}
& \text { Depurination ratio }=\frac{\text { Adenine }}{\text { IS }} \\
& \text { Depurination ratio }=\frac{\text { Guanine }}{\text { IS }}
\end{aligned}
$$

Apparatus. HPLC analy sis were performed using two Shimadzu LC-10AT pumps gradient-controlled HPLC system equipped with Shimadzu photo diode array detector (Model SPDM10A) and dual channel UV detection at $280 \mathrm{~nm}$ Analytes were eluted with a $4.6 \times 250 \mathrm{~mm} .5 \mu \mathrm{m}$ Waters XTerra $\mathrm{B} \mathrm{C}_{18}$ reverse phase analytical column using the following HPLC condition: Isocratically with $4 \%$ or $5 \%$ acetonitrile in water with $50 \mathrm{mM}$ ammonium formate. $\mathrm{pH} 6.9$. for 20 minutes at a flow rate of $1 \mathrm{~mL} / \mathrm{min}$ and $10 \mu \mathrm{L}$ injection volume for guanine-based or adenine-based nucleosides, respectively.

ESI LC/MS analy'ses were performed with a Finnigan LCQ Advantage $\bar{B}$ LC-MS/MS spectrometry utilizing Xcalibur $\bar{B}$ program. The samples were analy zed using $2.1 \times 150 \mathrm{~mm} .3 .5 \mu \mathrm{m}$ Waters XTerra: $C_{18}$ reverse phase analytical column using the following $\mathrm{LC}$ condition: Isocratically with $3 \%$ acetonitrile in water with $50 \mathrm{mM}$ ammonium fonmate. $\mathrm{pH} 6.9$. for 20 minutes at a flow rate of $0.18 \mathrm{~mL} / \mathrm{min}$ and $2 \mu \mathrm{L}$ injection volume. The mass spectrometer was operated in the positive polarity mode with ESI source type. Capillary voltage was controlled at $10 \mathrm{~V}$ and $270^{\circ} \mathrm{C}$ and Nitrogen gas was used as the sheath gas.

Centrifugation was done using Hanil Micro-12 (made in Korea) with maximum capacity $1.5 \mathrm{~mL} \times 12$, maximum speed $13.000 \mathrm{rpm}$. maximum RCF $10.770 \times \mathrm{g}$ and power AC $110 \mathrm{~V}$. $60 \mathrm{~Hz}$.

Statistical analysis. All the reactions were perfonned at least three times ( $n \geq 3$ ). The mean value \pm standard error (SE) was determined for each test. Student 's t-test was used to compare statistical significance of data. The significant values at either $\mathrm{P}<0.05\left(^{*}\right)$ or $\mathrm{P}<0.01\left(^{* *}\right)$ are represented by asterisks.

\section{Results}

Analysis of deadenylation of ddA induced by 1-BP or 2-BP by HPLC. Figure 2 shows the HPLC cluomatograns under the chromatographic condition described in material and methods for the analy sis of deadeny lation of ddA induced by 1-BP or 2-BP.

In Figure 2, chromatogram 1 indicates authentic adenine (Ade) at retention time of $6.20 \mathrm{~min}$. and chromatogram 2 indicates the mixture of ddA and 5-fuorouridine (5-FUri) utilized as an internal standard at retention times of 16.51 min and 4.69 min. respectively. Adenine ddA and 5-fuorouridine were well separated from the biological background under the described chromatographic condition. Chromatogram 3 indicates the mixture after incubation of ddA and excess amount ( 512 equivalent) of 1 -BP for $48 \mathrm{~h}$ at the physiological condition, which informs almost no change in amount of ddA and no production of adenine at that condition. Chromatogram 4 indicates the mixture after incubation of ddA and excess amount (5 12 equivalent) of 2-BP for $48 \mathrm{~h}$ at the phy siological condition. which indicates the peak of retention time at $16.51 \mathrm{~min}$ which corresponds to ddA completely disappeared and a peak of retention time at 6.20

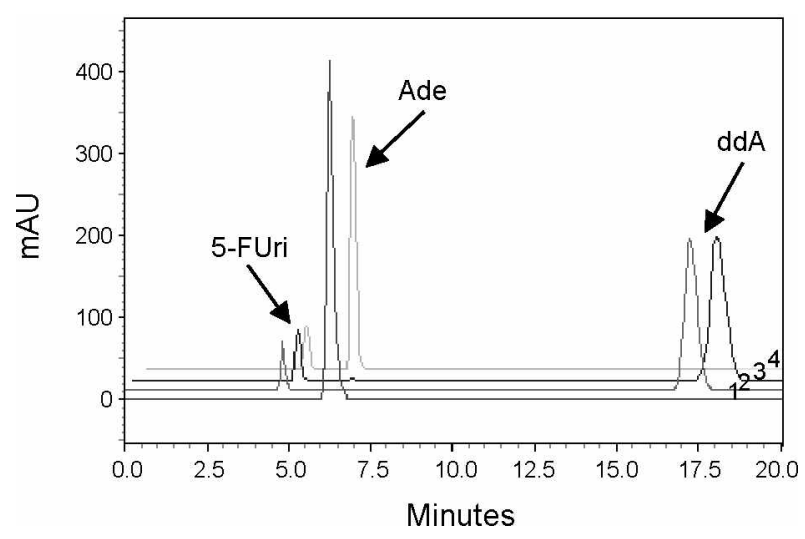

Figure 2. HPLC chromatogram of ( 1 ) adenine (Ade) (2) ddA +5-FUri, (3) $\mathrm{ddA}+5-\mathrm{FU} r+1-\mathrm{BP}(48 \mathrm{~h})$, and (4) $\mathrm{ddA}+5-\mathrm{FUri}+2-\mathrm{BP}(48 \mathrm{~h})$. Retention time for 5-FUn, Ade and ddA were 4.69,6.20 and 16.51 min, respectively under the HPLC condition mentioned in materials and methods.

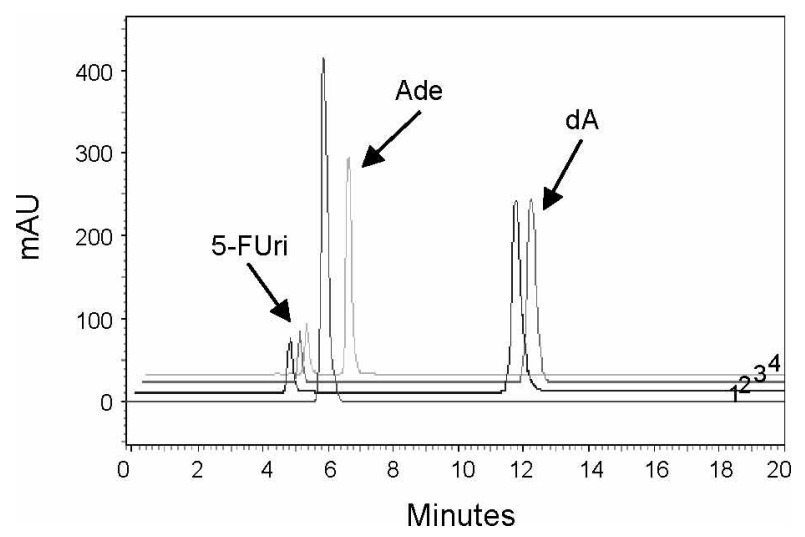

Figure 3. HPLC chromatogram of (1) adenine (Ade), (2) $\mathrm{dA}+$ 5-FUri, (3) dA + 5-FUri + l-BP (48 h) and (4) dA + 5-FUri + 2-BP (48 h). Retention time for 5-FUri, Ade and dA were 4.69,6.20 and $11.40 \mathrm{~min}$, respectively under the HPLC condition mentioned in materials and methods.

nin corresponding to adenine newly appeared. The results indicated that complete deadenylation occurred when ddA was incubated with excess amount of 2-BP for $48 \mathrm{~h}$.

Analysis of deadenylation of dA induced by 1-BP or 2-BP by HPL $C^{25}$. Figure 3 shows the HPLC chromatograms under the chromatographic condition described in material and methods for the analysis of deadenylation of dA induced by 1-BP or 2-BP.

In Figure 3, cluromatogram 1 indicates authentic adenine at retention time of $6.20 \mathrm{~min}$. and chromatogram 2 indicates the nixture of dAand 5-fuorouridine utilized as an internal standard at retention times of $11.40 \mathrm{~min}$ and $4.69 \mathrm{~min}$ respectively. Adenine. dA and 5-fuorouridine were well separated from the biological background under the described chromatographic condition. Chromatogram 3 indicates the mixture after incubation of $\mathrm{dA}$ and excess amount ( 512 equivalent) of 1 -BP for $48 \mathrm{~h}$ at the physiological condition. which infonms almost no change in amount of $\mathrm{dA}$ and no production of adenine at that condition. Chromatogram 4 indicates the nixture after incubation of $\mathrm{dA}$ and excess amount ( 512 equivalent) of 2-BP for $48 \mathrm{~h}$ at the physiological condition. which indicates the peak of retention time 
at $11.40 \mathrm{~min}$ which corresponds to dA completely disappeared and a peak of retention time at $6.20 \mathrm{~min}$ corresponding to adenine newly appeared. The results indicated that complete deaderrylation occurred when $d A$ was incubated with excess amount of 2-BP for $48 \mathrm{~h}$.

Analysis of deadenylation of adenosine induced by 1-BP or 2-BP by HPLC. Figure + shows the HPLC chromatograms under the chromatographic condition described in material and methods for the analysis of deadenylation of adenosine induced by 1 -BP or 2-BP.

In Figure 4. chromatogram 1 indicates authentic adenine at retention time of $6.20 \mathrm{~min}$. and chromatogram 2 indicates the mixture of adenosine and 5-fuorouridine utilized as an internal standard at retention times of $11.34 \mathrm{~min}$ and $4.69 \mathrm{~min}$. respectively. Adenine. adenosine and 5 -fuorouridine were well separated from the biological background under the described chromatographic condition. Chromatogram 3 indicates the mixture after incubation of adenosine and excess amount ( 512 equivalent) of 1-BP for $48 \mathrm{~h}$ at the physiological condition. which informs almost no change in amount of adenosine and no production of adenine at that condition. Chromatogram 4 indicates the mixture after incubation of adenosine and excess amount (512 equivalent) of 2-BP for 48 h at the physiological condition. which also indicates almost no change in amount of adenosine and no production of adenine at that condition. The results indicated that no deadeny lation occurred when adenosine was incubated with excess amount of 1-BP or 2-BP for $48 \mathrm{~h}$. In Figures 2.3 and 4. any change in amount of 5 -furouridine during incubation of ddA. dA and adenosine with 1-BP or 2-BP was not observed. which indicates the concentration of 5-fuorouridine was consistently well maintained and 5-fuorouridine was not affected by 1-BP. 2-BP or nucleosides.

Analysis of deguanylation of ddG induced by 1-BP or 2-BP by HPLC. Figure 5 shows the HPLC chromatograms under the chromatographic condition described in material and methods for the analysis of deguanylation of ddG induced by I-BP or 2-BP.

In Figure 5. chromatogram 1 indicates authentic guanine (Gua) at retention time of $4.87 \mathrm{~min}$. and chromatogram 2 indicates the mixture of ddG and 5 -fuorouracil ( 5 -FU) utilized as an internal standard at retention times of $12.83 \mathrm{~min}$ and 4.12 min. respectively. Guanine. ddG and 5-fuorouracil were well separated from the biological background under the described chromatographic condition. Chromatogram 3 indicates the mixture after incubation of ddG and excess amount ( 512 equivalent) of 1 -BP for $48 \mathrm{~h}$ at the physiological condition. which informs almost no change in amount of ddG and no production of guanine at that condition. Chromatogram 4 indicates the mixture after incubation of ddG and excess amount ( 512 equivalent) of 2-BP for $48 \mathrm{~h}$ at the phy siological condition, which indicates the peak of retention time at 12.83 min which corresponds to $\mathrm{ddG}$ completely disappeared and a peak of retention time at 4.87 min corresponding to guanine newly appeared. The results indicated that complete deguanylation occurred when ddG was incubated with an excess amount of 2-BP for $48 \mathrm{~h}$.

Analysis of deguanylation of $\mathrm{dG}$ induced by 1-BP or 2-BP by HPLC ${ }^{\text {?c }}$. Figure 6 shows the HPLC chromatograms under the chromatographic condition described in material and methods

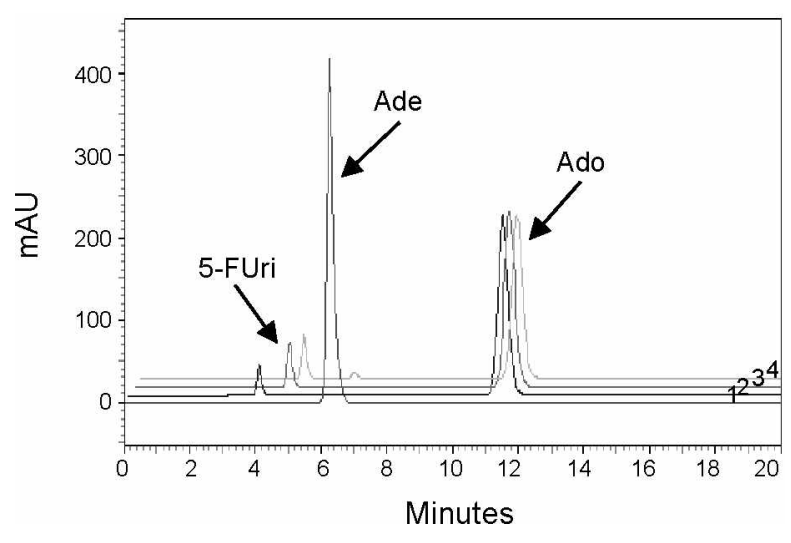

Figure 4. HPLC chromatogram of ( 1 ) adenine (Ade), (2) adenosine $(\mathrm{Ado})+5-\mathrm{FU}$, , (3) Ado + 5-FUn + 1-BP $(48 \mathrm{~h}$ ) and (4) Ado + 5-FUri $+2-\mathrm{BP}(48 \mathrm{~h})$. Retention time for 5-FUri, Ade and Ado were $4.69,6.20$ and $11.34 \mathrm{~min}$, respectively under the HPLC condition mentioned in materials and methods.

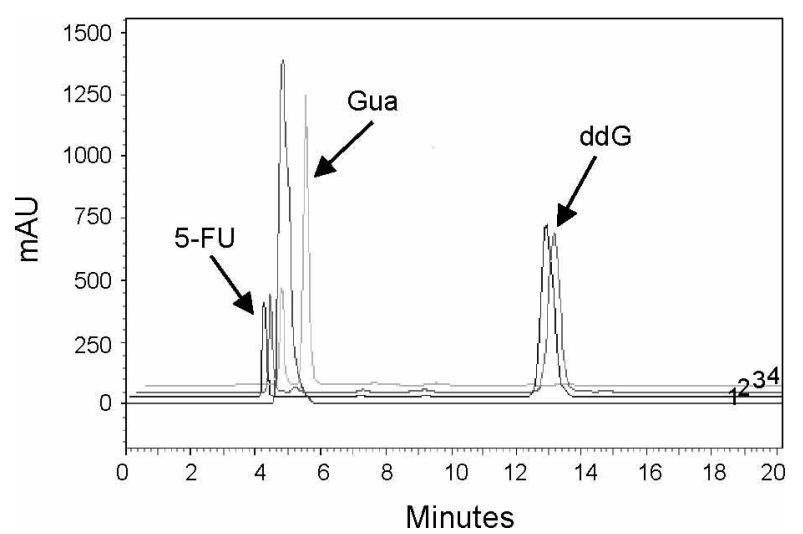

Figure 5. HPLC chromatogram of (1) guanine (Gua), (2) ddG + $5-\mathrm{FU},(3) \mathrm{ddG}+5-\mathrm{FU}+1-\mathrm{BP}(48 \mathrm{~h})$ and $(4) \mathrm{ddG}+5-\mathrm{FU}+2-\mathrm{BP}(48$ hi j. Retention time for 5-FU, Gua and ddG were 4.12,4.87 and 12.83 min, respectively under the HPLC condition mentioned in materials and methods.

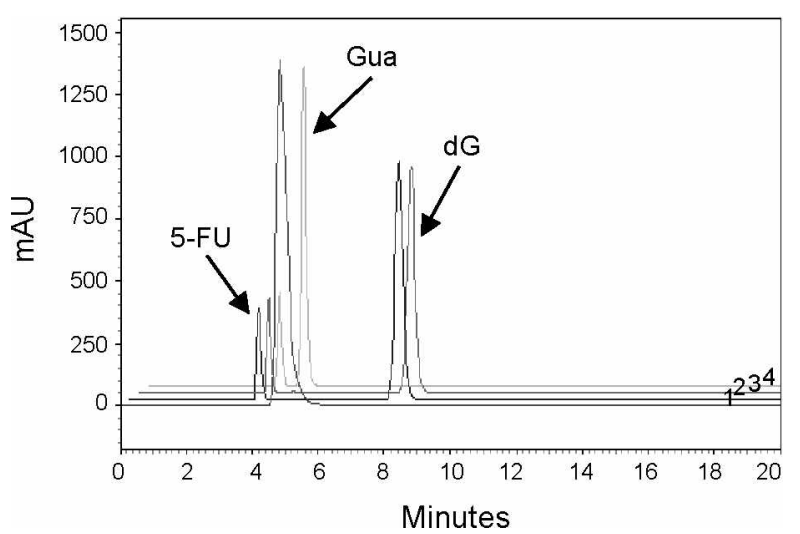

Figure 6. HPLC chromatogram of (1) guanine (Gual), (2) dG + 5-FU, (3) $\mathrm{dG}+5-\mathrm{FU}+\mathrm{l}-\mathrm{BP}(48 \mathrm{~h})$ and $(4) \mathrm{dG}+5-\mathrm{FU}+2-\mathrm{BP}(48 \mathrm{~h})$. Retention time for 5-FU, Gua and $\mathrm{dG}$ were $4.08,4.82$ and $8.38 \mathrm{~min}$ respectively, under the HPLC condition mentioned in materials and methods. 


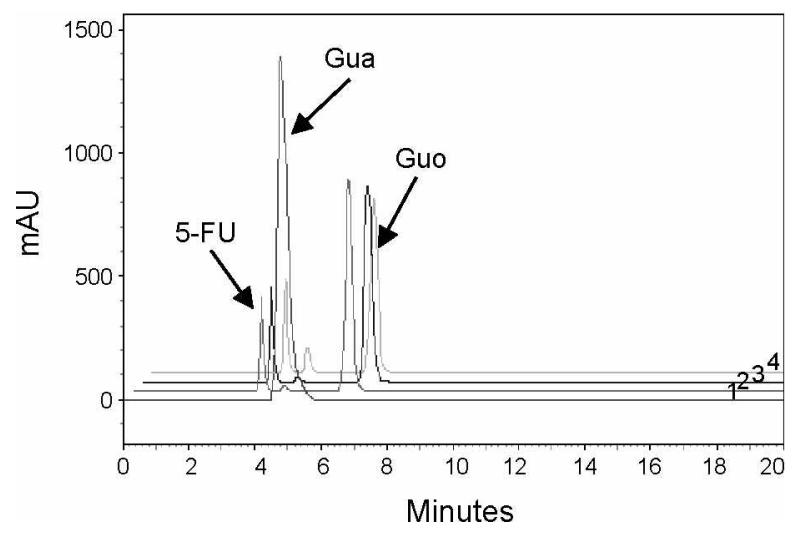

Figure 7. HPLC chromatogram of (1) guanine (Gua), (2) guanosine (Guo) + 5-FU, (3) Guo + 5-FU + 1-BP (48 h) and (4) Guo + 5-FU + 2-BP $(48 \mathrm{~h})$. Retention time for 5 -FU, Gua and Guo were $4.06,4.76$ and 6.70 min, respectively under the HPLC condition mentioned in materials and methods.

for the analy'sis of deguany lation of $\mathrm{dG}$ induced by 1-BP or 2-BP.

In Figure 6. chromatogram 1 indicates authentic guanine at retention time of $4.82 \mathrm{~min}$, and chromatogram 2 indicates the mixture of $\mathrm{dG}$ and 5 -fuorouracil utilized as an intemal standard at retention times of $8.38 \mathrm{~min}$ and $4.08 \mathrm{~min}$. respectively. Guanine. $\mathrm{dG}$ and 5-fuorouracil were well separated from the biological background under the described chromatographic condition. Chromatogram 3 indicates the mixture after incubation of $\mathrm{dG}$ and excess amount ( 512 equivalent) of 1-BP for $48 \mathrm{~h}$ at the plysiological condition, which informs almost no change in amount of $\mathrm{dG}$ and no production of guanine at that condition. Chromatogram 4 indicates the mixture after incubation of $\mathrm{dG}$ and excess amount (512 equivalent) of 2-BP for $48 \mathrm{~h}$ at the phy siological condition, which indicates the peak of retention time at $8.38 \mathrm{~min}$ which corresponds to $d G$ completely disappeared and a peak of retention time at $4.82 \mathrm{~min}$ corresponding to guanine new ly appeared. The results indicated that complete deguanylation occurred when $\mathrm{dG}$ was incubated with an excess amount of 2-BP for $48 \mathrm{~h}$.

Analysis of deguanylation of guanosine induced by 1-BP or 2-BP by HPLC. Figure 7 shows the HPLC chromatograms under the chromatographic condition described in material and methods for the analysis of deguanylation of guanosine induced by 1 -BP or 2 -BP.

In Figure 7. chromatogram 1 indicates authentic guanine at retention time of $4.76 \mathrm{~min}$. and chromatogram 2 indicates the mixture of guanosine and 5 -fiorouracil utilized as an internal standard at retention times of $6.70 \mathrm{~min}$ and $4.06 \mathrm{~min}$. respectively. Guanine. guanosine and 5 -fuorouracil were well separated from the biological background under the described chromatographic condition. Chromatogram 3 indicates the mixture after incubation of guanosine and excess amount (512 equivalent) of $1-B P$ for 48 h at the plysiological condition, which informs almost no change in amount of guanosine and no production of guanine at that condition. Chromatogram 4 indicates the mixture after incubation of guanosine and an excess amount (512 equivalent) of 2-BP for $48 \mathrm{~h}$ at the phy'siological condition. which also indicates almost no change in amount of guanosine and only small amount of production of guanine at that condition. The
Table 1. Preliminary reaction of $1-B P$ and $2-B P$ with ddA, dA and adenosine at the physiological condition for 48 hrs.

\begin{tabular}{cccc}
\hline Haloalkanes & DR $(\%)$ in ddA & LR $(\%)$ in dA & $\begin{array}{c}\text { DR }(\%) \text { in } \\
\text { adenosine }\end{array}$ \\
\hline 1-BP & -1.62 & 1.37 & 1.74 \\
2-BP & 100.00 & 100.00 & 4.60 \\
\hline
\end{tabular}

One mg of nucleoside (ddA. dA and Adenosine) was dissolved in $\mathrm{ImL}$ phosphate buffered saline solution (PBS) in $5 \mathrm{~mL}$ vial. Ten $1 \mathrm{~mL}$ PBS) of 5-flurouridine was added as an intemal standard. It was then incubated with excess amount ( 512 equiralents) of 1 - BP or 2-BPat the physiological condition for $48 \mathrm{~h}$, which was analyed by HPLC and further confiimed by LC-MS MS

Table 2. Preliminary reaction of 1-BP and 2-BP with $\mathrm{ddG}, \mathrm{dG}$ and guanosine at the physiological condition for $48 \mathrm{hrs}$.

\begin{tabular}{cccc}
\hline Haloalkanes & DR $(\%)$ in ddG & DR $(\%)$ in dG & $\begin{array}{c}\text { DR }(\%) \text { in } \\
\text { gulanosine }\end{array}$ \\
\hline 1-BP & 6.9 & 1.54 & 6.70 \\
2-BP & 100.00 & 100.00 & 13.66 \\
\hline
\end{tabular}

One $\mathrm{mg}$ of nucleoside (ddG. $\mathrm{dG}$ and guanosine) was dissolved in $\mathrm{lmL}$ phosphate buffered saline solution (PBS) in $5 \mathrm{~mL}$ vial. Twenty $\mu \mathrm{L}$ (10 $\mathrm{mg}$ in $1 \mathrm{~mL}$ PBS ) of 5-flurouracil was added as an internal standard. It was then incubated with excess amount ( $\$ 12$ equivalents) of $1-\mathrm{BP}$ or $2-\mathrm{BP}$ at the phy siological condition for $48 \mathrm{~h}$, which was analyzed by HPLC and further confirmed by LC-MS MS.

results indicate that no deguanylation occurred when guanosine was incubated with excess amount of l-BP or 2-BP for $48 \mathrm{~h}$. In Figures 5.6 and 7, any change in amount of 5-fuorouracil during incubation of ddG. $\mathrm{dG}$ and guanosine with 1-BP or 2-BP was not observed, which indicates the concentration of 5-fuorouracil was consistently well maintained and 5 -fuoroumcil was not affected by 1-BP. 2-BP or nucleosides. From the HPLC analysis, it was found that $100 \%$ depurination occurred in ddA. dA. ddG and dG by excess amount of 2-BP at the physiological condition for $48 \mathrm{hr}$. However. almost no depurination was observed in adenosine and guanosine by 2-BP. In addition. no depurination was also observed in nucleosides by l-BP. which was sunmmarized in Table 1 and 2 .

Analysis of time iesponse depurination of ddA, dA, ddG and dG induced by 2-BP. Figure 8 shows time response curves of depurination rate of ddA. dA ddG or dG induced by 2-BP according to time. Figure 8(a) indicates time response curve of deadenylation after incubation of ddA and 512 dose equivalent of 2-BP at the physiological condition at a time interval of $\mathrm{l} \mathrm{h}$. Deadenylation begin to occur at $5 \mathrm{~h}$ and drastically increase until $9 \mathrm{~h}$ in time dependent manner. Complete deadenylation occurred at $10 \mathrm{~h}$. Figure $8(\mathrm{~b})^{35}$ indicates time response curve of deadenylation after incubation of $\mathrm{dA}$ and 512 dose equivalent of 2-BP at the phy'siological condition at a time interval of $3 \mathrm{~h}$. Deadenylation begin to occur at $6 \mathrm{~h}$ and drastically increase until $18 \mathrm{~h}$ in time dependent manner. Complete deadenylation occurred at $21 \mathrm{~h}$. Comparing deadenylation rates of ddA and dA. deadenylation rate of ddA was much faster than that of $d A$. Figure 8(c) indicates time response curve of deguanylation after incubation of ddG and 512 dose equivalent of 2-BP at the physiological condition at a time interyal of $1 \mathrm{~h}$. Deguany lation begin 
(a)

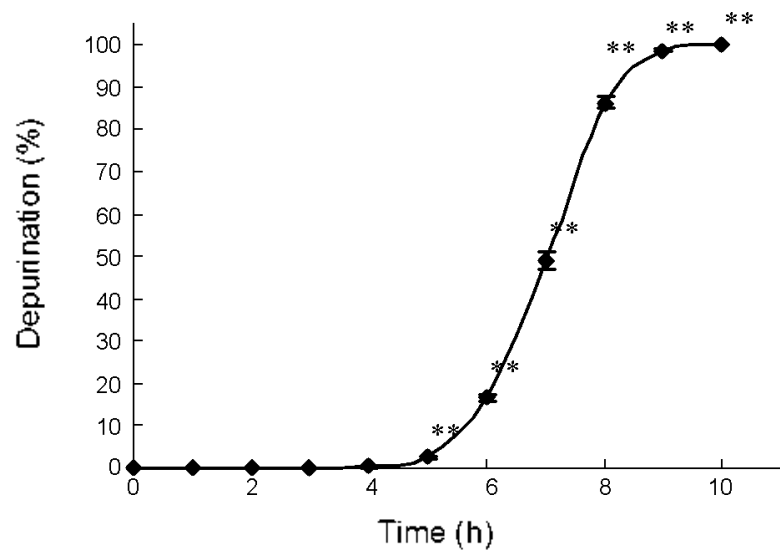

(c)

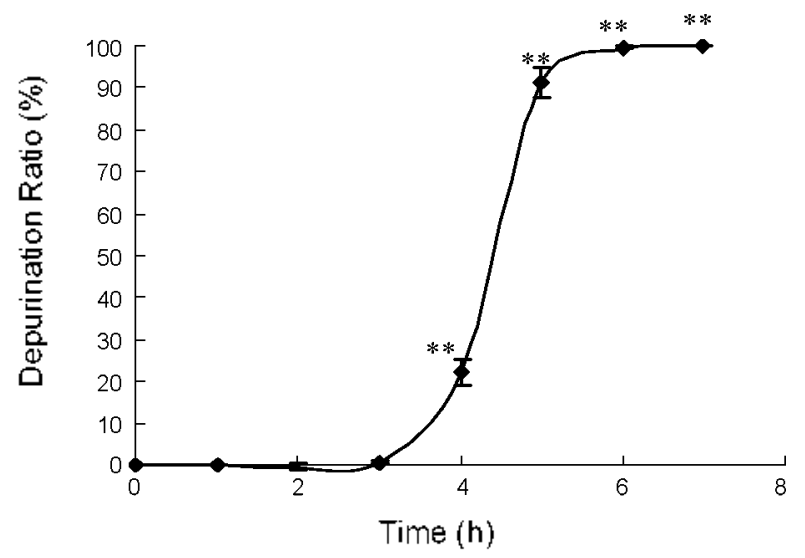

(b)

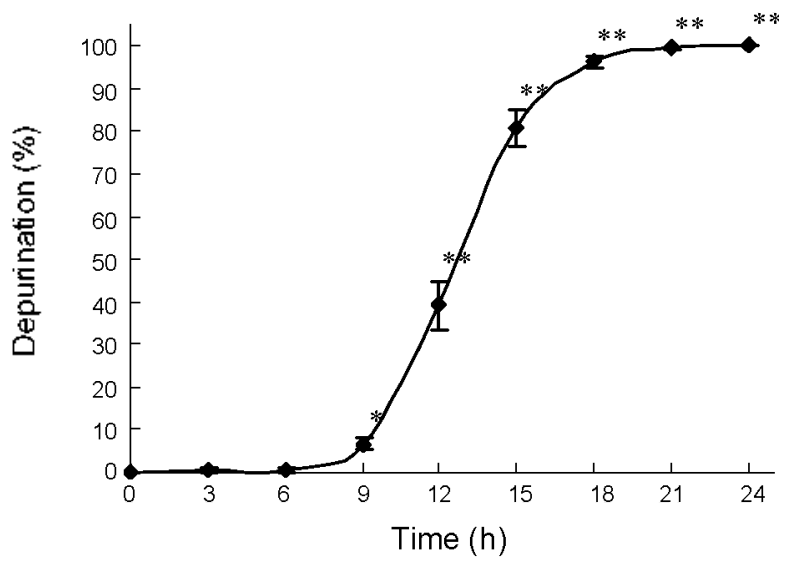

(d)

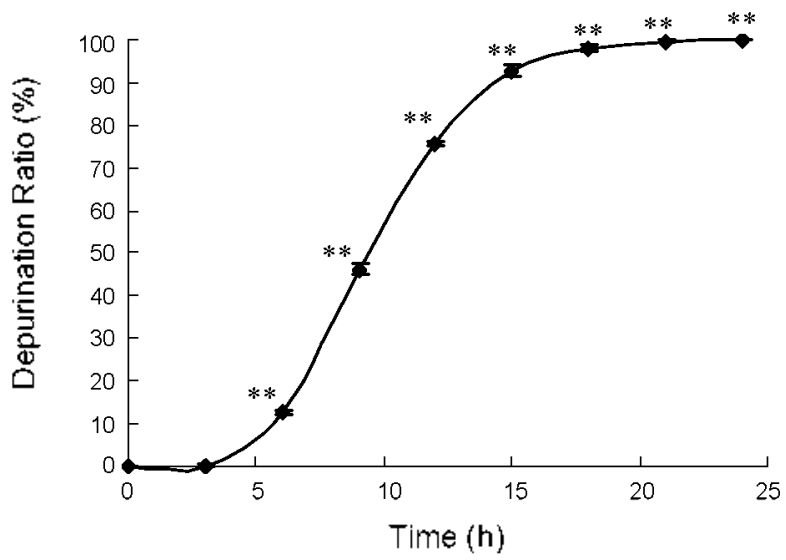

Figure 8. Time response curves of (a) ddA (b) dA (c) ddG and (d) dG with 2-BP. Time response reactions were performed with the 512 equivalents of 2-BP at a time interval of 1 and 3 h until the time at which $100 \%$ depurination occurred for dideoxy and deosy nucleosides, respectively. Then it was analyzed by HPLC following the condition mentioned in the materials and methods.

to occur at $3 \mathrm{~h}$, and drastically increase until $5 \mathrm{~h}$ in time dependent manner. Complete deguany lation occurred at $6 \mathrm{~h}$. Figure $8(\mathrm{~d})^{\hat{s}^{5}}$ indicates time response curve of deguany lation after incubation of $\mathrm{dG}$ and 512 dose equivalent of 2-BP at the physiological condition at a time interval of $3 \mathrm{~h}$. Deguanylation begin to occur at $3 \mathrm{~h}$. and drastically increase until $15 \mathrm{~h}$ in time dependent manner. Complete deguanylation occurred at $18 \mathrm{~h}$. Comparing deguanylation rates of $\mathrm{ddG}$ and $\mathrm{dG}$. deguanylation rate of $\mathrm{ddG}$ was mich faster than that of $\mathrm{dG}$. Regarding depurination rates of ddA, dA. ddG and dG. the order of depurination rate was observed as $d d G>d d A>d G>d A$

Analysis of dose response depurination of ddA, dA, ddG and dG induced by 2-BP. Figure 9 shows dose response curves of depurination rate of ddA ddG. dA or $\mathrm{dG}$ induced by 2-BP according to dose. Figure 9 (a) indicates dose response curve of deadeny lation after incubation of ddA and different dose equivalent of 2-BP at the physiological condition for $24 \mathrm{~h}$. Deadeny lation begin to occur at 4 dose equivalent of 2-BP and drastically increase until 16 dose equivalent of 2-BP in dose dependent manner. Complete deadenylation occurred at 32 dose equivalent of 2-BP. Figure $9(\mathrm{~b})^{\hat{2}^{5}}$ indicates dose response curve of deadenylation after incubation of $\mathrm{dA}$ and different dose equivalent of 2-BP at the physiological condition for $2+\mathrm{h}$. Deadenylation begin to occur at 2 dose equivalent of 2-BP, and drastically increase until 16 dose equivalent of 2-BP in dose dependent manner.
Complete deadenylation occurred at 32 dose equivalent of 2-BP. Figure $9(\mathrm{c})$ indicates dose response curve of deguanylation after incubation of ddG and different dose equivalent of 2-BP at the phy siological condition for $24 \mathrm{~h}$. Deguanylation begin to occur at 8 dose equivalent of 2-BP. and drastically increase until 128 dose equivalent of 2-BP in a dose dependent manner. Complete deguanylation occurred at 256 dose equivalent of 2-BP. Figure $9(\mathrm{~d})^{25}$ indicates dose response curve of deguany lation after incubation of $\mathrm{dG}$ and different dose equivalent of 2-BP at the physiological condition for $24 \mathrm{~h}$. Deguanylation begin to occur at 2 dose equivalent of 2-BP. and drastically increase until 16 dose equivalent of 2-BP in a dose dependent manner. Conplete deguanylation was occurred at 32 dose equivalent of 2-BP.

Analysis of time iesponse depurination of calf thymus DNA induced by 2-BP. Figure 10 shows time response curves of depurination rate of calf thymus DNA induced by 2-BP according to time. The formation of adenine and guaune from calf thymus DNA by treatment with $128 \mu \mathrm{L}$ of $2-\mathrm{BP}$ was observed in time response mamer.

Analysis of dose response kepurination of calf thymus DNA induced by 2-BP. Figure 11 shows dose response curves of depurination rate of calf thy mus DNA induced by 2-BP according to dose. The formation of adenine and guanine from calf thynus DNA by treatment with 2-BP was observed in dose response manner for $48 \mathrm{~h}$. 
(a)

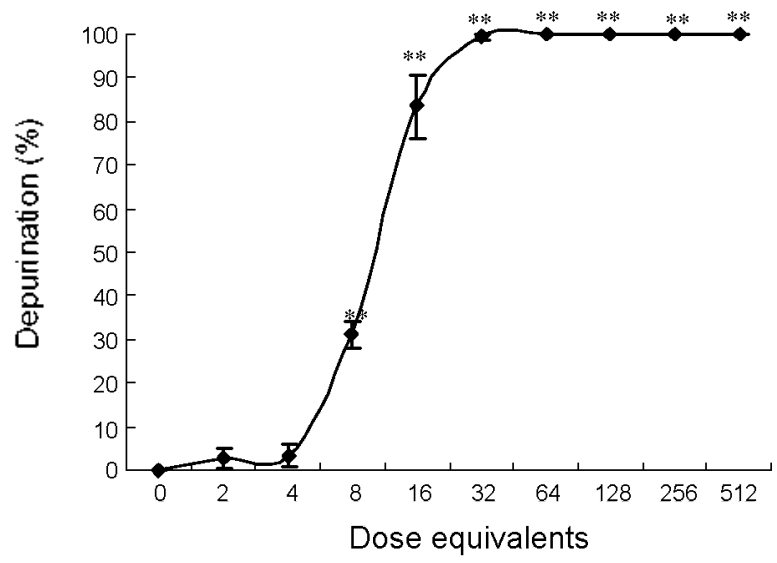

(c)

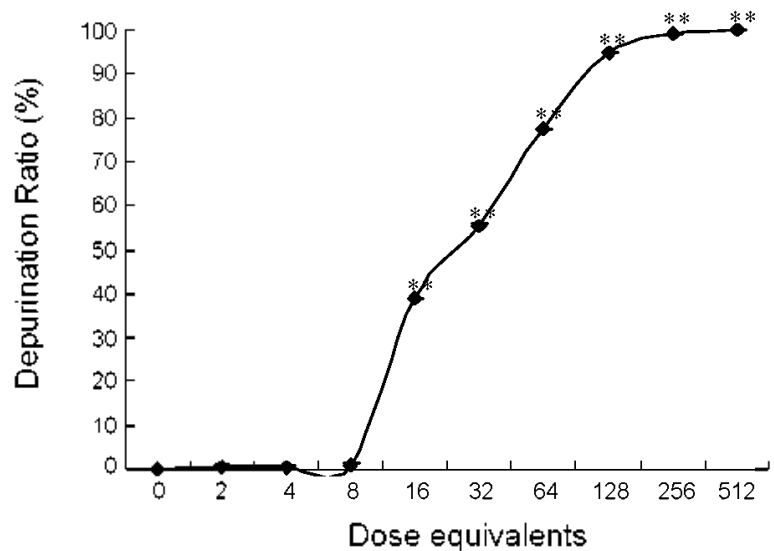

(b)

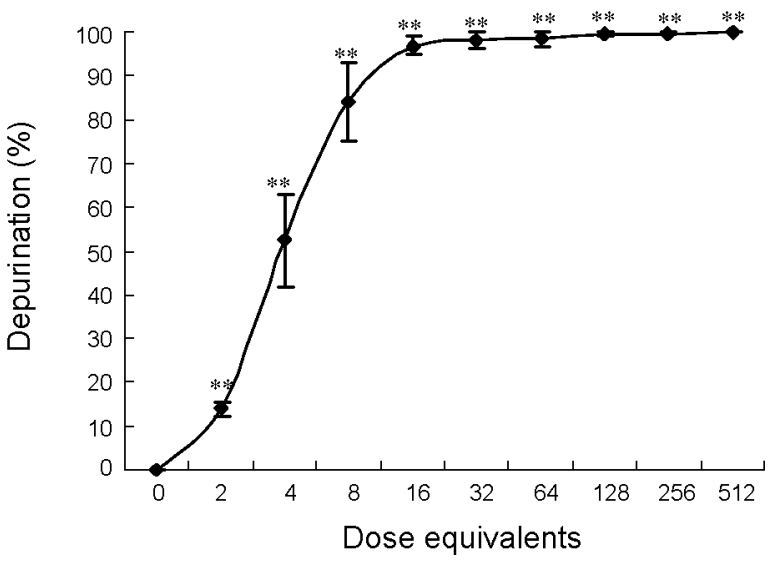

(d)

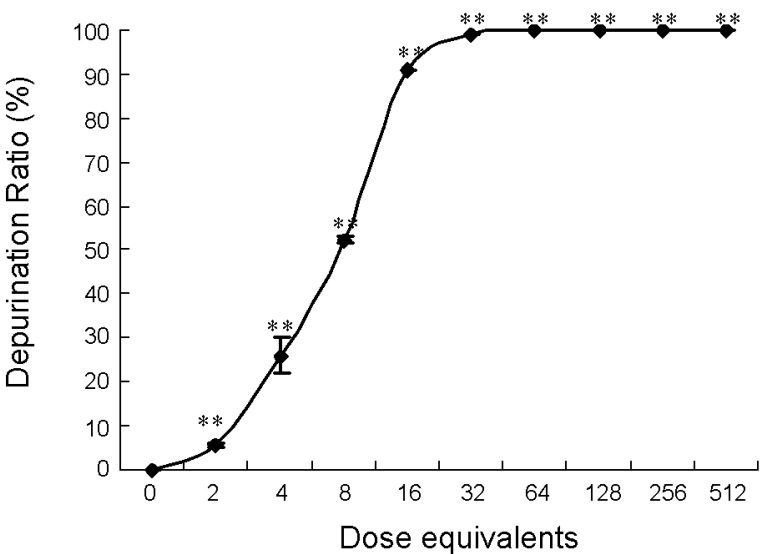

Figure 9. Dose response curves of (a) ddA and (b) dA (c) ddG and (d) dG with 2-BP. Dose response reactions were performed with the 0. 2, 4. $8,16,32,64,128,256$ and 512 equivalents of 2 -BP for $24 \mathrm{~h}$. Then it was analyzed by HPLC with the condition mentioned in the materials and methods.

\section{Discussion}

Depurination ratio (\%) in nucleosides was calculated on the basis of the decreased amount of nucleosides in percentage by comparing the integration value of the nucleosides in HPLC using the formula mentioned in materials and methods. The depurinated products of nucleosides (ddA, dA, ddG and dG) are adenine and guanine, respectively. Since the solubility of guanine is relatively low at physiological condition. the guanine formed after depurination precipitates in $\mathrm{pH} 7.4$ buffer solution, which decreases the accuracy of depurination ratio if we apply the increasing amount of depurinated product (adenine or guanine) for the determination of depurination ratio. Therefore, we applied the decreasing amounts of nucleosides for the determination of depurination ratio. Meanwhile. depurination ratio in calf thymus DNA was calculated on the basis of the increased amount of adenine or guanine by comparing the integration value between increased adenine or glanine and internal standard in EIC from LC-MS/MS using the formula mentioned in materials and methods. Since guanine is soluble in acidic condition. $\mathrm{I}$ M aqueous $\mathrm{HCl}$ was added to dissolve the precipitated guanine before analy sis. In Figures 2, 3 and t. chromatogram 1 shows the peak of authentic adenine as references. chromatogram 2 shows that of adenine based-nucleosides. ddA. dA or adenosine. along with the peak of internal standard chromatogram 3 and 4 show the peaks of products formed after incubation of ddA, dA or adenosine with l-BP or 2-BP for $48 \mathrm{~h}$, respectively. In Figures 5,6 and 7. chromatogran 1 shows the peak of authentic guanine as references. chromatogram 2 shows that of guanine based-nucleosides. ddG. dG or guanosine. along with the peak of internal standard, cluromatogram 3 and 4 show the peaks of products formed after incubation of ddG. $\mathrm{dG}$ or guanosine with 1-BP or 2-BP for $48 \mathrm{~h}$. respectively. It is evident that the peaks of ddA, dA, ddG or dG completely disappeared and the peaks of adenine or guanine have appeared after incubation with 2-BP for $48 \mathrm{~h}$ (chromatogran 4 in Figures 2, 3. 5 and 6). However almost no change of chromatogram was observed after incubation of nucleosides with l-BP for $48 \mathrm{~h}$ (cluromatogram 3 in Figures 2. 3. 4. 5.6 and 7) or incubation of adenosine and guanosine with 2 -BP for 48 h (chromatogram 4 in Figures 4 and 7 ). These results indicated that $100 \%$ depurination occurred in ddA, dA, ddG and dG by 2-BP. but practically no depurination occurred by $1-B P$ (Tables 1 and 2). In addition. only small amount of depurination occurred by incubation of adenosine or guanosine with 2-BP.

Time and dose response reaction with ddA, dA, ddG and $\mathrm{dG}$ by 2-BP indicated that depurination increased in time and dose dependent manner (Figures 8 and 9). In time response reaction. depurination increased in time dependent manner, and complete depurination was observed after $10 \mathrm{~h}$ in ddA. $6 \mathrm{~h}$ in ddG and $21 \mathrm{~h}$ in both dA and dG by 2-BP (Figure 8 ). Comparing depurination rates among nucleosides according to time. the 


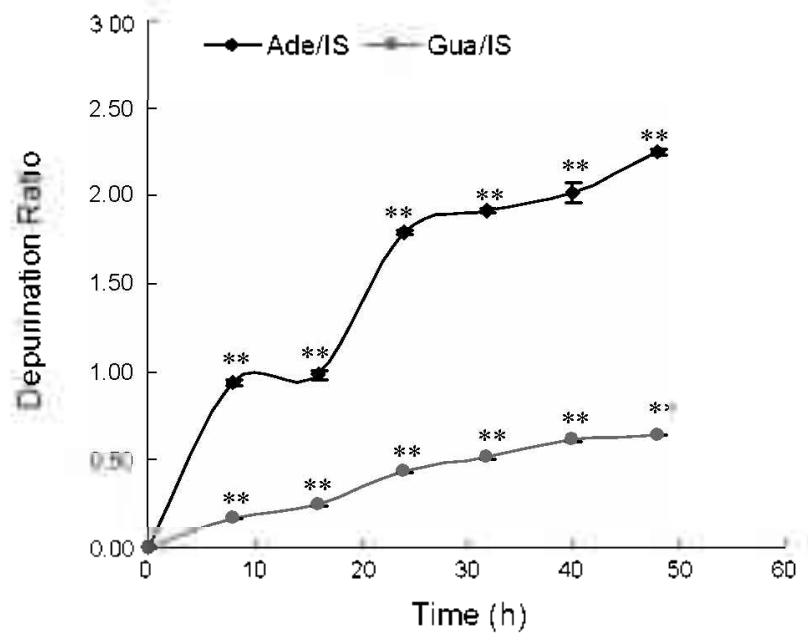

Figure 10. Time response curves of calf thymus DNA with 2-BP. Time response reactions were performed with the $128 \mu \mathrm{L}$ of $2-\mathrm{BP}$ at a time interval of $8 \mathrm{~h}$ for $48 \mathrm{~h}$. Then it was analyzed by LC-MS/MS following the condition mentioned in the materials and methods.

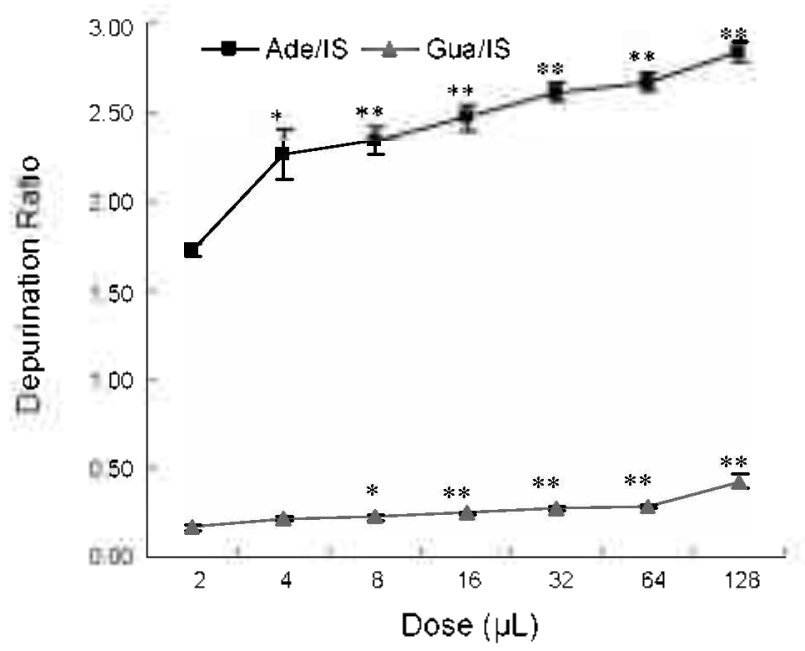

Figure 11. Dose response curves of calt thymus DNA with 2-BP. Dose response reactions were $p$ erformed with the $2,4,8,16,32,64$ and $128 \mu \mathrm{L}$ of 2 -BP for $48 \mathrm{~h}$. Then it was analyzed by LC-MS/MS with the condition mentioned in the materials and methods.

order of depurination rates was observed as $\mathrm{ddG}>\mathrm{ddA}>\mathrm{dG}>$ dA. which is in accordance with the result reported by Kochetkor. ${ }^{? 6}$ He reported that depurination was highest with dideoxy followed by deoxy and then ribose nucleosides which follow that 2-deoxyribosyl derivative are hydrolyzed $100-1000$ times faster than the comesponding ribosyl derivatives. Depurination was also found to be greater in case of guanine based nucleosides than adenine based nucleosides which also follow the order of reactivity given by Kochetkov: deoxyglanosine > deoxyadenosine $>>$ guanosine $>$ adenosine $>$ dexoycytidine $>$ deoxythymidine $>>$ cy tidine $=$ uridine ${ }^{-6-3: 3)}$.

In dose response reaction depurination increased in dose dependent manner. and complete depurination was observed with both 32 dose equivalents for $2+$ h incubation in ddA $\mathrm{dA}$ and $\mathrm{dG}$. and 128 dose equivalents for $24 \mathrm{~h}$ incubation in ddG (Figure 9).

Time and dose response reaction with calf thy mus DNA by
2-BP indicated that depurination increased in time and dose dependent manner (Figures 10 and 11 ). In case of the calf thymus DNA the rate of depurination of $\mathrm{dA}$ is faster than $\mathrm{dG}$. This may be explained by that guanine is bound to cytosine with three $\mathrm{H}$-bonds whereas adenine is bound to thymine with two $\mathrm{H}$-bonds in double stranded DNA. which makes adenine easy to detach from the chain.

\section{Conclusion}

We observed depurination of ddA. dA. ddG and $d G$ induced by 2-BP as a probable mechanism of toxicity. In terns of rate of depurination. dideoxy showed the highest reactivity followed by deoxy and then ribose nucleosides. Although the exact mechanism of depurination is not known, it shows that lydroxyl group in the sugar moiety of the nucleosides plays an important role in rate of depunination. It was also found that 2-BP showed faster rate of depurination than l-BP. which indicated that secondan' alky'l halide displayed greater reactivity than primary alky' halide in the rate of depurination. Since the mechanism of depurination is unknow $n$ at the present time. a study to elucidate mechanism of depurination is in progress.

Aclnowledgments. This research was supported by the Yeungnam University research grants in 2007.

\section{Refelences}

1. Kunkel, T. A. Proc Notl Acod. Sci. LSA $1984,81,1494$

2. Vousden, K. H.; Bos, J. L.; Marsheall, C. J.; Phillips, D. H. Proc. Vatl Acad Sci. USA 1986, 83, 1222.

3. Lindahl, $\mathrm{T} ;$; Andersson, A. Biochemistry 1972, 11,3618 .

4. Lindahl, T. Am, Rev: Biochem. 1982, 51,61

5. Drake, J. W: Baltz, R. H. Am. Rev Biochent 1976, 45, I1

6. Schaaper, R. M. Leob, L. A. Proc. Natl Acad Sci. LSA 1981 , 78,1773 .

7. Schataper, R. M.; Glickman. B. W.: Loeb. L. A. Whtat. Res. 1982. 106, 1

8. Schaaper. R. M: Loeb. L. A. Mhtat. Res. 1982, 105. 19

9. Loeb, L. A. Cell 1985, 40,483

10. Schaaper, R. M.; Kunkel, T. A; Loeb, L. A. Proc. Katl Acad. Sci. US. 1 1983, 80,487.

11. Chakravarti, D.; Mailander, P. C.: Li, K. M.; Higginbatham, S.; Zhang, H. L.: Gross, M. L.: Meza, J. L.: Cavalieri, E. L.: Rogan, E. G. Oncongene 2001, 20,7945.

12. Chakravarti, D.; Mailander, P. C.; Cavalieri, E. L.; Rogan, E. G. Mutat. Res. $\mathbf{2 0 0 0}, 456,17$

13. HSDB. Hazardous Substances Data Bank, Bethesda (MD). National Institutes of Health, 2001. Available from URL. http://to.unet.nlm. nih.gov/cgi-bin/sis/htmlgen?HSDB.

14. Kim, Y.; Jung, K.; Hwang, T.; Jung, G.; Kim, H.; Park, J.; Kim, J.; Park, J.; Park, D.; Park, S.; Choi, K.; Moon, Y. Scand. J. Work Environ. Health 1996, 22,387.

15. Kim. Y.: Park, J.: Moon, Y. Toxicol Letr. 1999, 108, 309

16. Park, J. S.: Kim, Y.; Park, D. W.; Choi, K. S.: Park, S. H.: Moon, Y. H. J. Occup. Health 1997, 39, 138

17. Ichihara, G.; Ding, X.: Yu, X.; Wu, X.; Kamijima, M.; Peng, S.; Jiang. X.; Takeuchi, Y. Am. J. Ind. Med. 1999, 35, 523

18. Yu, X.; Ichihara, G.: Kitoh, J.: Xie, Z.; Shibata, E.: Kamijima, M.: Asaleda, N.: Hisanaga, N.: Takenchi, Y. Toxicolog, 1999. 135,87

19. Takeuchi, Y.; Ichihara, G.: Kamijima, M. J. Occup. Heolth 1997, 39,179 .

20. The exposure criteria of chemical and phy sical factors, Korean 
Ministry of Labor, 1998.

21. Patty, F. A. Industrial Hygiene and Toxicologv. Irish, D. D., Ed.: Interscience: New York, 1962: Vol. 2, p 1249.

22. Sax, N. I. Dangerous Properties of Industrial Materials; Van Nostrand Reinhold: New York, 1968; p 923

23. Sekiguchi, S: Suda, M: Zhai, Y. L.; Honma, T. Toricol Lett 2002, 126,41

24. Zhao, L.-X.: Kin, E.-K.: Lim, H.-T: Moon, Y.-S.: Kim, N.-H.; Kim, T.-H.; Choi, H: Chae, W.; Jeong, T. C.; Lee, E. S. Arch. Pharm. Res. 2002, 25, 39 .
25. Thapa, P.: Sherchan, J.: Karki, R., Jeong, T. C.: Lee, E. S. J. Appl. Phamacol. 2007, 15, 224.

26. Kochetkov, N. K.; Budovskii. E. I. Organic Chemistry of Nucleic Acids; Plenum: New York, 1972; p 425.

27. Singer, B.; Grunberger, D. Molecular Biology of Mutagens and Carcinogens; Plenum: New York, 1983; 16-96.

28. Zoltewicz. I. A.: Clark. D. F.: Sharpless, T. W. Grahe. G. J. Am. Chem. Soc. 1970, 92, 1741.

29. York, J. L. J. Org. Chem. 1981, 16, 2171 .

30. Garrett, E. R.; Mehta, P. I. J. Am. Chem. Soc. 1972, 97, 8542. 